\title{
Influence of Electrode Material and EDM Parameters on Electrode Wear of AISI H13 Steel
}

\author{
Mostafa Adel Abdullah ${ }^{1}$, Nareen Hafidh Obaeed ${ }^{2}$, Aseil Mohammed Radhi ${ }^{3}$, Hiba Adil Ahmed ${ }^{4}$ \\ 1,2 Assistant Lecturer, Dept. of Production Engineering and Metallurgy, University of Technology/Baghdad. Iraq. \\ 3,4 Assistant Lecturer, Dept. of Production Engineering and Metallurgy, University of Technology/Baghdad. Iraq. \\ **Corresponding author Email mostafa_ad_87@yahoo.com \\ Submitted: $17 / 5 / 2017$ \\ Accepted: $\quad 8 / 8 / 2018$
}

\begin{abstract}
Electrical discharge machining (EDM) is a non-traditional process that uses the electrical spark discharge to machine electrically conducting materials for geometrically complex shapes or hard materials. In the current work, cupper and brass were used as the electrode material, and AISI H13 steel as the workpiece. Different input parameters were investigated namely: 20, 30, 40 A current, 50,100,150 $\mu$ s pulse on time, and 1, 3, $6 \mathrm{~mm}$ gap. The workpiece thickness was fixed to $4 \mathrm{~mm}$ and the pulse off time was $25 \mu \mathrm{s}$. All EDM experiments were carried out in diesel oil and the voltage was $140 \mathrm{~V}$.

The results showed that the electrode wear decreased with increasing the pulse on time and gap and increased with increasing current for copper and brass electrode. The optimal conditions for minimum tool wear were: pulse on time $150 \mu \mathrm{s}$, current $20 \mathrm{~A}$, and gap $6 \mathrm{~mm}$ for copper and brass electrodes. Electrode wear is minimum for copper at all parameter values compared to brass electrode.
\end{abstract}

\section{Keywords: Electrical discharge machining (EDM), Electrode wear (EW), Electrode material, Taguchi method.}

\section{INTRODUCTION}

Electrical discharge machining (EDM) (also known as spark machining) has been one of the most widely used non-conventional manufacturing process for machining hard metal. EDM is considered to be classified as an electro-thermal machining process, in that the thermal energy resulted from the electric discharge (the spark) is utilized in removing materials from the workpiece. The EDM is effectively utilized to reshape materials that are significantly hard, high temperature resistance and electrically conductive El-Hoffy, 2005. The typical setting of any EDM experiment involves motivating an electric spark between two conductive electrodes separated by a dielectric liquid. The spark gap between the electrodes ranges from $0.02 \mathrm{~mm}$ to $0.5 \mathrm{~mm}$. One of the electrodes is called the tool while the other is called the workpiece. A series of rapidly repeating discharges can lead to a controlled erosion for the work material Shukry \& Vian2015, the temperature accompanying to these high intensity electric discharges are high enough to cause material removal and to lead to a melt or evaporation into the electrodes Abbas Fadhil et.al.2016. Ranjith.R\&Rakesh.N ,2016. An attempt was made using electric discharge machining (EDM) to optmise the output parameters such as surface roughness (Ra), material removal rate (MRR), and tool wear rate (TWR) by varying the input parameters such as peak current (Ip), pulse on time (Ton) and pulse off time (Toff) by using AISI H13 steel material with copper electrode. Response Surface Methodology (RSM) is applied to design the number of experiments and the results are analyzed by using analysis of variance (ANOVA). The result showed that MRR increases with increase in current and pulse on time and pulse off time didn't show significant contribution, the TWR also increased with increasing in current but decreased with increasing in pulse on time. Whereas, pulse off time didn't show a significant contribution and surface roughness increased with increasing in current and pulse on time and decreased with pulse off time, Rajneesh Kumar, et al ,2014. Another work studied the effect (Pules on, discharge current and gap voltage) in die sinking EDM on tool wear by using rectangular mild steel .All the experiments were conducted on a $\mathrm{Z}$ numerically controlled (ZNC) for machining time (10 minutes). The result showed that the effect of current on tool. Tool wear increased with increasing in current tool wear decreased with increase in Ton, Harpreet Singh \&Amandeep Singh ,2012. Other researchers have compared the material removal rate (MRR) use electric discharge machining (EDM) with different tool materials (copper and brass electrode) and material (AISI D3) was used as workpiece with parameter pulse on, pulse off and fix time period of $(20 \mathrm{~min})$. The dielectric fluid for all the experiments is used kerosene oil. Their result

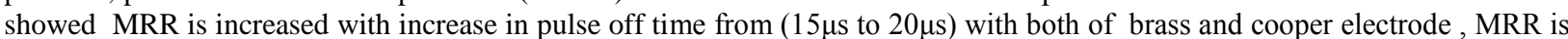
decreased with increase in pulse on time from $(50 \mu \mathrm{s}-100 \mu \mathrm{s})$ in case of brass electrode and decrease in copper electrode A. A. Khan 2008 In this study an analysis has been done to evaluate the electrode wear along the cross-section of an electrode during EDM of aluminum and mild steel workpiece using copper and brass as electrodes. The dielectric fluid for all the experiments is used kerosene oil. The result shown Electrodes undergo more wear compared to that along its length ,EW increases with increase in current and voltage, electrodes subjected more wear in machining of mild steel than machining of aluminum, EW increases with increase in current and gap voltage Vg, and MRR increases sharply with increase in current. 


\section{EXPERIMENTAL WORK}

A- Workpiece materials

Among various tool steel grades, AISI H13 Steel with dimensions of (40*40) mm and thickness of $4 \mathrm{~mm}$ has been selected for the experimental work. Density and Surface Roughness Ra of AISI H13 steel are $0.0078 \mathrm{~g} / \mathrm{mm}^{3}$ and (3.09) $\mu \mathrm{m}$ respectively. Workpiece was inspected in (Central Organization for Standardization and Quality Control). The chemical composition is listed in Table 1. The experiments were conducted on EDM CM323C which is available in the Training and Workshop Center / University of Technology / Baghdad as showed in Fig 1. And Fig 2. Show workpiece after cut.

TABLE (1): CHEMICAL COMPOSITION OF WORKPIECE MATERIAL.

\begin{tabular}{|c|c|c|c|c|c|c|c|c|}
\hline $\begin{array}{c}\text { Elemen } \\
\text { ts }\end{array}$ & $\mathrm{C}$ & $\mathrm{Si}$ & $\mathrm{M} \mathrm{n}$ & $\mathrm{P}$ & $\mathrm{S}$ & $\mathrm{Cr}$ & $\mathrm{Mo}$ & $\mathrm{Fe}$ \\
\hline percent & 0.45 & 1.2 & 1.75 & 0.03 & 0.03 & 12 & - & $\begin{array}{c}\text { balanc } \\
\mathrm{e}\end{array}$ \\
\hline
\end{tabular}

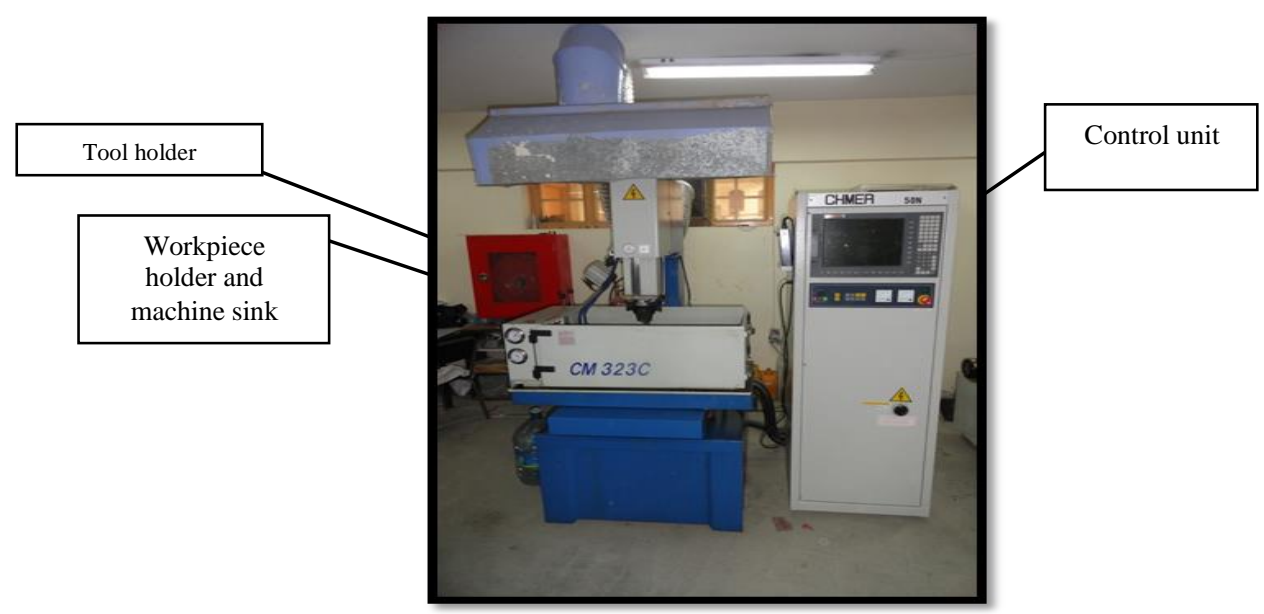

Fig. 1. EDM CM323C machine.

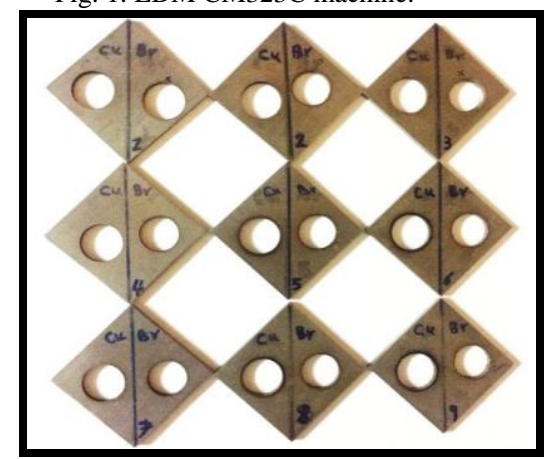

Fig. 2. Workpiece after cut

\section{B-Tool (Electrode) materials}

Two types of tool were used in the experimental study, pure copper $99 \%$ and pure brass $99 \%$ electrodes made as a rod with diameter $(15 \mathrm{~mm})$ and length $(40 \mathrm{~mm})$, as shown in Fig 3 and Fig 4.

-Copper:- Surface Roughness $=($ Tool side $=0.66$, Tool Face $=3.07) \mu \mathrm{m}$.

-Brass:- Surface Roughness $=($ Tool side $=0.43$, Tool Face $=4.11) \mu \mathrm{m}$. 
C-Selection of machining parameters
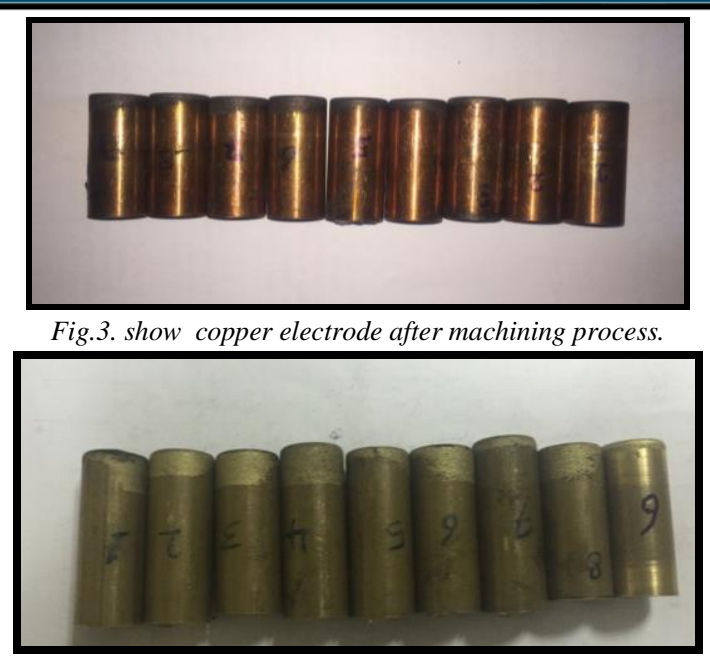

Fig.4. show brass electrode after cutting process.

The design is used to determine the number of parameter experiments that be needed. Pulse on time, gap and current are considered to be the main variable of this machining process at three differed levels. Based on Taguchi Method the partial number of experiments is nine (L9). The levels of control parameters are listed in Table 2.

TABLE (2): THE MACHINING PARAMETERS.

\begin{tabular}{|c|c|c|c|c|c|c|}
\hline \multirow[b]{2}{*}{ No } & \multirow{2}{*}{$\begin{array}{l}\text { Machining } \\
\text { parameters }\end{array}$} & \multirow[b]{2}{*}{ Symbol } & \multirow[b]{2}{*}{ unit } & \multicolumn{3}{|c|}{ Levels } \\
\hline & & & & Level 1 & Level 2 & Level 3 \\
\hline 1 & Pulse on time & $\mathrm{T}_{\text {on }}$ & $\mu \mathrm{s}$ & 50 & 100 & 150 \\
\hline 2 & Gap & $\mathrm{G}$ & $\mathrm{mm}$ & 1 & 3 & 6 \\
\hline 3 & Current & $\mathrm{I}_{\mathrm{p}}$ & A & 20 & 30 & 40 \\
\hline
\end{tabular}

D- Tool wears (Tw) measurement

Tool Wear (TW) measured used nine experiments have been conducted on two types of electrode with some different values of discharging currents. The machining condition is selected the voltage (140A) feed (0.6mm) up and dawn, pulse off time $(25 \mu \mathrm{s})$.The tool weight was also computed before and after machining. The Eq. (1) being used to determine the experimental metal removal rate is given below [1]:

$$
\text { TW }=\frac{\text { Weight befor machining-Weight after machining }}{\text { Time duration }}
$$

\section{E- Machining times measurement}

Machining time is given in (CHMER EDM) machine. On the other hand, the calculated machining time differs from one sample to another depending on current and thicknesses of workpiece.

\section{RESULTS \& DISCUSSION}

This discussion mainly divided into two parts, the first part will concentrate on the effect of machining parameter (pules on time, gap and current) on electrode wear (EW) by using steel H13 as a workpiece material at thickness of $(4 \mathrm{~mm})$ using copper electrode with diameter $(15 \mathrm{~mm})$. The second part using brass electrode with a diameter (15 $\mathrm{mm})$.

A- Main Effects Using (ANOVA) for Copper

Fig 5 shows the main effect parameter in tool wear as output Ton, Current and Gap as input, with increases (Ton and Gap) lead to decreasing tool wear. Increases (current) lead to increases tool wear , with the expansion of current density, the release zone temperature increment because of which the temperature of dielectric liquid increments. The results indicat the optimal conditions. The minimum EW is (0.0092): Ton at level-3(150 $\mu \mathrm{s})$, Current at level-1(20 A), and Gap at level-3(6 mm). 
TABLE (3). WEAR MEASURED OF COPPER TOOL

\begin{tabular}{|c|c|c|c|c|c|c|c|}
\hline No & $\begin{array}{c}\text { Pulse on time } \\
\text { Ton( } \mu \mathrm{s})\end{array}$ & $\begin{array}{c}\text { Current } \\
\mathrm{I}_{\mathrm{P}}(\mathrm{A})\end{array}$ & $\begin{array}{c}\text { Gap } \\
\mathrm{G}(\mathrm{mm} \\
)\end{array}$ & $\begin{array}{c}\mathrm{W} \\
\text { before }(\mathrm{g} \\
)\end{array}$ & $\begin{array}{c}\mathrm{W} \text { after } \\
(\mathrm{g})\end{array}$ & $\begin{array}{c}\text { Time } \\
(\mathrm{min})\end{array}$ & $\begin{array}{c}\text { TW } \\
(\mathrm{g} / \mathrm{min})\end{array}$ \\
\hline 1 & 50 & 20 & 1 & 69.194 & 68.406 & 18.20 & 0.0486 \\
\hline 2 & 50 & 30 & 3 & 69.673 & 69.031 & 13.44 & 0.0617 \\
\hline 3 & 50 & 40 & 6 & 69.308 & 68.71 & 12.46 & 0.0480 \\
\hline 4 & 100 & 20 & 3 & 69.151 & 69 & 16.20 & 0.0093 \\
\hline 5 & 100 & 30 & 6 & 69.568 & 69.344 & 12.50 & 0.0179 \\
\hline 6 & 100 & 40 & 1 & 69.972 & 68.959 & 9.41 & 0.0754 \\
\hline 7 & 150 & 20 & 6 & 68.041 & 67.939 & 17.12 & 0.0092 \\
\hline 8 & 150 & 30 & 1 & 69.196 & 69.011 & 11.44 & 0.0162 \\
\hline 9 & 150 & 40 & 3 & 69.409 & 69.131 & 12.17 & 0.0303 \\
\hline
\end{tabular}

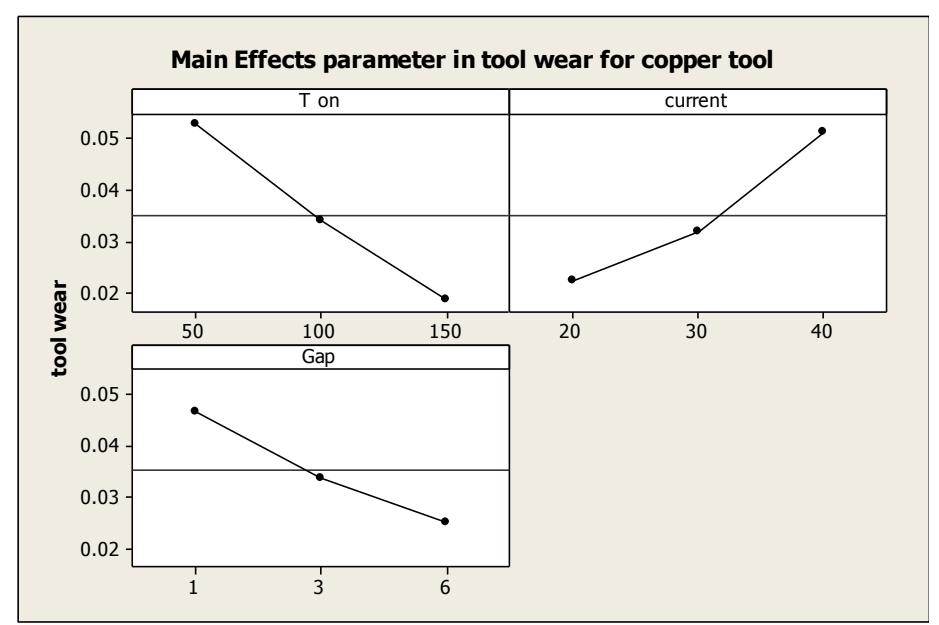

Fig.5. THE EFFECT OF CURRENT, PULSE ON TIME AND GAP ON EW USING COPPER ELECTRODE.

\section{B- Main Effects Using (ANOVA) for Brass}

Fig 6 shows the main effect parameter in tool wear as output ton, current and gap as input, with increases (Ton and Gap) lead to decreasing Tool Wear and increases (current) lead to increases Tool Wear. The results show the optimal conditions for minimum TW were the minimum EW is (0.2047): Ton at level-3(150 $\mu$ s), Current at level1(20 A), and Gap at level-3(6 mm).

comparison of (EW) between copper electrode and for brass electrode with same steel H13 workpiece and same cutting parameter for nine sample as shown in Table (3) and Table (4) the results shown brass electrode is more electrode wear than copper electrode as shown Fig 7. In brass electrode maximum wear at sample (2) with $(0.4980) \mathrm{g} / \mathrm{min}$ and minimum at sample ( 7) with $(0.2047) \mathrm{g} / \mathrm{min}$, while in copper maximum wear at sample (7) with $(0.0754) \mathrm{g} / \mathrm{min}$ and minimum at sample ( 8$)$ with $(0.0092) \mathrm{g} / \mathrm{min}$. 
TABLE (4): SHOWN THE TOOL WEAR MEASURED FOR BRASS TOOL

\begin{tabular}{|c|c|c|c|c|c|c|c|}
\hline No & $\begin{array}{c}\text { Pulse on } \\
\text { time Ton }(\mu \mathrm{s} \\
)\end{array}$ & $\begin{array}{c}\text { Curren } \\
\mathrm{t} \\
\mathrm{I}_{\mathrm{P}}(\mathrm{A})\end{array}$ & $\begin{array}{c}\text { Gap } \\
\mathrm{G}(\mathrm{mm} \\
)\end{array}$ & $\begin{array}{c}\mathrm{W} \\
\text { before}(\mathrm{g} \\
)\end{array}$ & $\begin{array}{c}\mathrm{W} \\
\text { after } \\
(\mathrm{g})\end{array}$ & $\begin{array}{c}\text { Time } \\
(\mathrm{min} \\
)\end{array}$ & $\begin{array}{c}\text { TW } \\
(\mathrm{g} / \mathrm{min} \\
)\end{array}$ \\
\hline 1 & 50 & 20 & 1 & 65.939 & 55.383 & $\begin{array}{c}24.4 \\
8\end{array}$ & 0.4312 \\
\hline 2 & 50 & 30 & 3 & 64.78 & 60.507 & $\begin{array}{c}17.0 \\
3\end{array}$ & 0.4980 \\
\hline 3 & 50 & 40 & 6 & 63.259 & 57.585 & 12.3 & 0.4613 \\
\hline 4 & 100 & 20 & 3 & 65.303 & 58.582 & $\begin{array}{c}23.4 \\
7\end{array}$ & 0.2864 \\
\hline 5 & 100 & 30 & 6 & 65.597 & 62.501 & $\begin{array}{c}12.5 \\
8\end{array}$ & 0.2461 \\
\hline 6 & 100 & 40 & 1 & 64.837 & 57.034 & 8.58 & 0.4582 \\
\hline 7 & 150 & 20 & 6 & 65.891 & 61.951 & 19.2 & 0.2047 \\
\hline 8 & 150 & 30 & 1 & 61.228 & 58.003 & 9.3 & 0.3468 \\
\hline 9 & 150 & 40 & 3 & 63.312 & 59.122 & 10.6 & 0.3953 \\
\hline
\end{tabular}

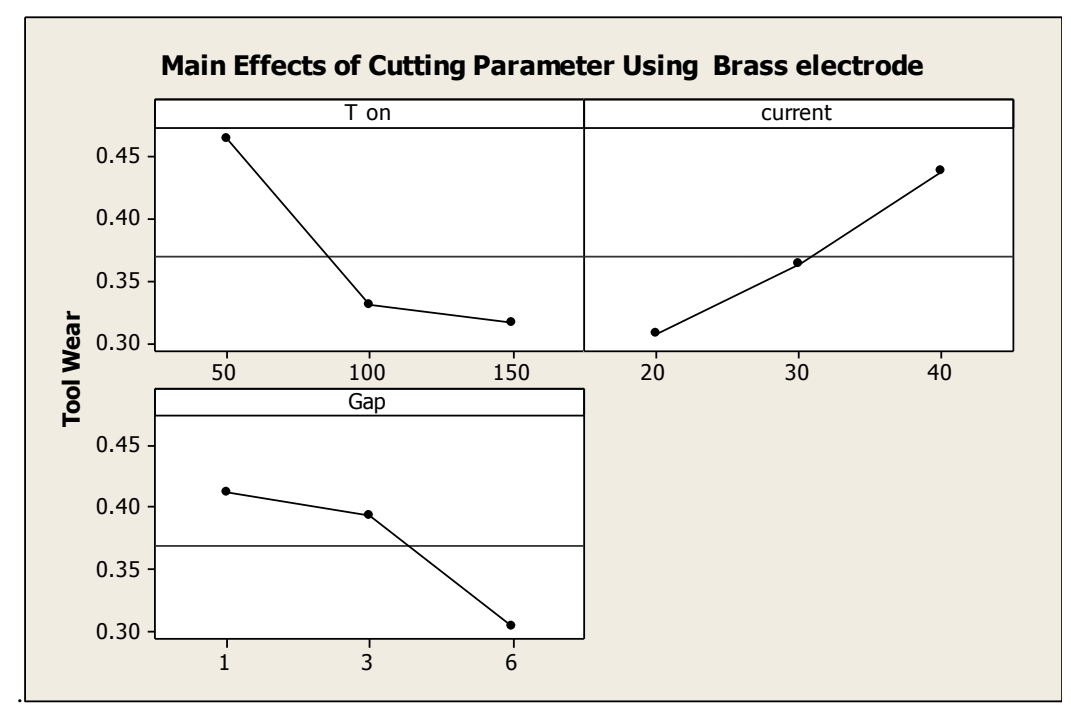

Fig.6. THE EFFECT OF CURRENT, PULSE ON TIME AND GAP ON EW USING BRASS ELECTRODE. 


\section{CONCLUSION}

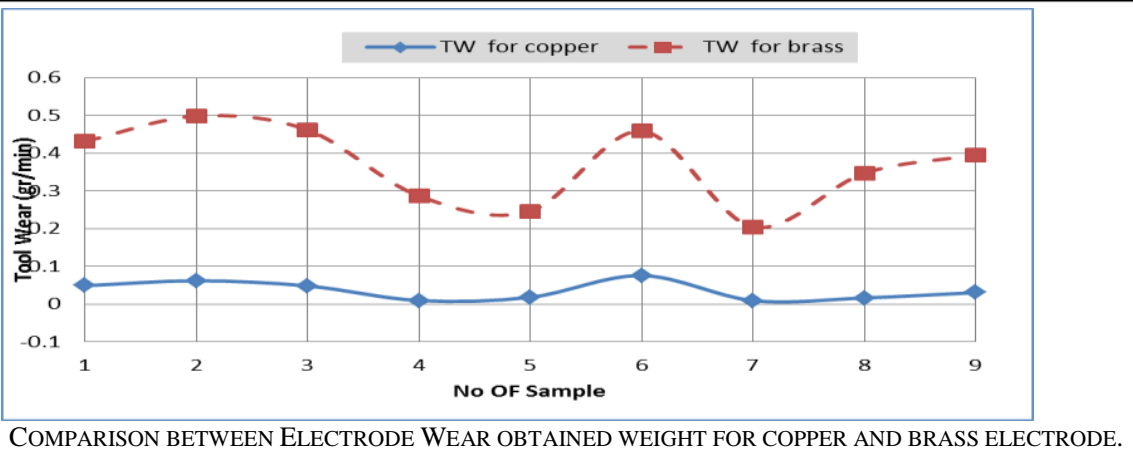

This research used Taguchi's design (minimum number of experiments can use this method) for getting optimum parameter with lowest Tool Wear,.

- From the experiments, the maximum EW in copper tool $(0.0754)$ at $\mathrm{T}_{\text {on }}(100 \mu \mathrm{s})$, gap $(1 \mathrm{~mm})$ and $\mathrm{I}_{\mathrm{p}}(40 \mathrm{~A})$. The minimum EW is $(0.0092)$ at $\mathrm{T}_{\text {on }}(150 \mu \mathrm{s})$, Gap $(6 \mathrm{~mm})$ and $\mathrm{I}_{\mathrm{p}}(20 \mathrm{~A})$.

- From the experiments, the maximum EW in brass tool $(0.4980)$ at $\mathrm{T}_{\text {on }}(50 \mu \mathrm{s})$, gap $(3 \mathrm{~mm})$ and $\mathrm{I}_{\mathrm{p}}(30 \mathrm{~A})$. The minimum EW is $(0.2047)$ at $\mathrm{T}_{\text {on }}(150 \mu \mathrm{s})$, Gap $(6 \mathrm{~mm})$ and $\mathrm{I}_{\mathrm{p}}(20 \mathrm{~A})$.

- Optimal conditions for minimum TW were: Ton at level-3(150 $\mu \mathrm{s})$, Current at level-1(20 A), and Gap at level-3(6 mm), Fig 5. and Fig 6. of copper and brass electrode.

- Comparison between results of (EW) obtained weighting for copper electrode and for brass electrode with same steel H13 workpiece and same cutting parameter for nine samples as shown in Table 3. and Table 4. the results shown brass electrode is more wear than copper.

\section{REFERENCES}

[1] El-Hoffy"Advanced Machining Processes "Chapter Five, pp.115-140, by McGraw-Hill Company,2005.

[2] Dr.Shukry Hammed Aghdeab \& Vian Nihad Najm" The Influence of Current \& Pulse off Time on Material Removal Rate and Electrode Wear Ratio of Steel 304 in EDM " Eng. \&Tech.Journal, Vol.33, No.8, 2015.

[3] Dr.Abbas Fadhil Ibrahim, Mostafa Adel Abdullah and Safaa Kadhim Ghazi" Prediction of Surface Roughness and Material Removal Rate for 7024 AL-Alloy in EDM Process" Eng. \&Tech.Journal, Vol.34, No.15,2016.

[4] Ranjith.R\& Rakesh.N " Experimental Investigation and Optimization of Process Parameters of Electrical Discharge Machining with H13 Steel " International Journal of Innovative Research in Science, Engineering and Technology,vol. 5, April 2016.

[5] Rajneesh Kumar, Om Prakash Sahani, Meghanshu Vashista" Effect of EDM Process Parameters on Tool Wear " Journal of Basic and Applied Engineering Research, Vol. 1, No. 2, pp. 53-56, October 2014.

[6] Singh,H.\& Singh,A" Effect of Pulse On/Pulse Off Time On Machining Of AISI D3 Die Steel Using Copper And Brass Electrode In EDM " International Journal of Engineering and Science, Vol. 1,PP 19-22, November 2012.

[7] Khan.A. A"Electrode wear and material removal rate during EDM of aluminum and mild steel using copper and brass electrode" Springer-Verlag London Limited, 2008. 